\title{
PROFISSIONAL NUTRICIONISTA: SUA PERCEPÇÃO SOBRE AS COBRANÇAS EXTERNAS RELACIONADAS À SUA IMAGEM CORPORAL E ESTEREÓTIPOS ${ }^{1}$
}

Cristina dos Santos Lovato ${ }^{2}$ Alice da $\mathrm{Cruz}^{3}$

RESUMO: Na constituição do perfil profissional, muitas pessoas deparam-se com estereótipos relacionados, na maioria das vezes, à aparência corporal considerada como um critério para a avaliação da qualidade profissional dos indivíduos. Nesse contexto, o objetivo deste estudo foi verificar se há interferência de estereótipos na percepção do profissional nutricionista e se há um perfil almejado para ele pelo mercado de trabalho. Tratou-se de um estudo quanti-qualitativo realizado por meio de respostas a um questionário semiestruturado, o qual foi disponibilizado via o aplicativo do Google "Formulários Google" e enviado para nutricionistas e por intermédio de análises documentais de seletivas de emprego para nutricionistas nos sites Agrobase oportunidade, Indeed e Trabalha Brasil. Os resultados da pesquisa indicaram que parece haver um alinhamento entre a aparência física, em termos de padrão antropométrico, e a percepção sobre a área em conformidade com os padrões estéticos vigentes de magreza. Constatou-se, por fim, que o estereótipo de magreza parece ser um aspecto constitutivo da identidade do nutricionista.

Palavras-chave: Nutrição. Perfil profissional. Imagem corporal. Estereótipo.

\section{NUTRITIONIST PROFESSIONAL: YOUR PERCEPTION ON EXTERNAL CHARGES RELATED TO YOUR BODY IMAGE AND STEREOTYPES}

ABSTRACT: In the constitution of the professional profile many people are faced with stereotypes related, in most cases, to the body appearance considered as a criterion for the assessment of the professional quality of individuals. In this context, the objective of this study was to verify whether there is interference from stereotypes in the perception of the nutritionist and whether there is a profile desired for him in the job market. It was a quantitative and qualitative study carried out by means of responses to a semi-structured questionnaire, which was made available via Google's application "Google Forms" and sent to nutritionists and through documentary analyzes of selective jobs for nutritionists on the websites Agrobase oportunidade, Indeed and Trabalha Brasil. The survey results indicated that there appears to be an alignment between physical appearance, in terms of anthropometric pattern, and the perception of the area in accordance with the current aesthetic standards of thinness. It was found, finally, that the stereotype of thinness seems to be a constitutive aspect of the nutritionist's identity.

\footnotetext{
1 Uma versão prévia deste estudo intitulada Estereótipos femininos e a percepção sobre a identidade profissional do nutricionista foi apresentada e defendida para a obtenção do título de Bacharel em Nutrição pela Universidade Federal do Pampa, campus Itaqui-RS, pela coautora desse artigo.

2 Docente na Universidade Federal do Pampa (UNIPAMPA), campus Itaqui, do curso Bacharelado Interdisciplinar em Ciências e Tecnologias, Doutora em Letras - Estudos linguísticos pelo Programa de PósGraduação em Letras da Universidade Federal de santa Maria. E-mail: cristinalovato@unipampa.edu.br.

${ }^{3}$ Acadêmica na Universidade Federal do Pampa (UNIPAMPA), campus Itaqui, no curso de Bacharelado em Nutrição. E-mail: alicedacruz96@gmail.com.
} 
Keywords: Nutrition. Professional profile. Body image. Stereotype.

\section{INTRODUÇÃO}

A aparência corporal vem sendo considerada um critério para a avaliação da qualidade profissional, embora esse aspecto não seja determinante para isso (MELO et al., 2017; BELLIZZI, HASTY, 1998). Juízos estéticos não emitem conceitos, eles são o "resultado de uma mera reação pessoal do contemplador frente ao objeto, e não diante das propriedades deste" (FREITAS et al., 2010, p. 391). Melo et al. (2017) destaca que a pessoa obesa, por exemplo, é associada à preguiça e considerada desleixada, indisciplinada, não confiável, insalubre, sem cuidado e insegura, mas também alegre e extrovertida. Todavia, esses atributos não seriam considerados relevantes para o mercado de trabalho. Pessoas com excesso de peso são normalmente as mais prejudicadas por generalizações estereotipadas (BELLIZZI; HASTY, 1998).

Questões que envolvem a satisfação com o corpo "remetem a cobranças sociais que exigem perfis antropométricos cada vez mais magros e podem ser relacionadas à aceitação social e ao sucesso profissional, gerando constante insatisfação com a aparência física" (FREITAS et al., 2010 p.737). Desse modo, parece haver uma relação intrínseca entre obesidade e padrão de beleza corporal: uma relação de negação, em que a obesidade simboliza o velho, o passado e cede seu lugar à magreza, "que é a novidade e, portanto, preferida; sua influência é no sentido de significar o indesejado pela sociedade, o que as pessoas devem evitar" (FREITAS et al., 2010 p. 393), no caso, a obesidade. Freitas et al. (2010, p. 393) pontua que, com as novas tecnologias para a reprodução de imagens, chegaram também novas imagens; essas mostram corpos em uma nova forma: mais magros. Tais imagens são produzidas em escala característica da sociedade, "perpassando todas as classes sociais, as imagens fazem do corpo um fenômeno de moda".

$\mathrm{Na}$ contemporaneidade, observa-se que a imagem corpórea almejada exige, portanto, "uma adequação a parâmetros antropométricos aceitáveis ao padrão biomédico e estético defendido pela mídia" (ARAUJO et al., 2015, p. 2788). Vannuchi, citado em Freitas et al. (2010, p. 39), destaca que as mulheres brasileiras são as responsáveis por posicionar o Brasil entre os 10 maiores mercados de cosméticos do mundo; as brasileiras "perdem apenas para as japonesas no quesito insatisfação com a aparência física". Cinquenta e 
quatro por cento das brasileiras já cogitaram a hipótese de cirurgia plástica, e $7 \%$ já se submeteram a esse procedimento, o que configura o maior número entre os países pesquisados (FREITAS et al., 2010). Isso reforça o valor social que a aparência física assume na cultura brasileira.

O culto ao corpo e a exigência de estar dentro dos padrões físicos pré-estabelecidos na sociedade fazem com que a profissão de nutricionista passe a ser um dos fatores determinantes para alcançar tais objetivos como se adaptar, por exemplo, aos padrões antropométricos vigentes. A sociedade parece estar marcada por valores como o consumismo, o individualismo, a busca pelo sucesso e o acúmulo de bens materiais. Nesse contexto, o corpo tornou-se também objeto de consumo, há um culto ao corpo, e ele está diretamente associado à imagem de poder, à beleza e à mobilidade social (IRIART et al., 2009; BOSI et al., 2006). O cuidado com o corpo, com o próximo, com o lar, com a alimentação e com a família associa a profissão Nutrição ao universo feminino. O Conselho Federal de Nutricionistas (CFN), ao buscar traçar o perfil do profissional da Nutrição no país, confirma esse aspecto e indica que 94,1\% desses profissionais são mulheres (CFN, 2018).

Quanto à interface entre aparência física e profissão, essa relação, muitas vezes, baseia-se em estereótipos sociais que, por vezes, geram altos níveis de estigma por divergirem dos padrões pré-estabelecidos. O conceito de estigma, como uma situação na qual o indivíduo está inabilitado para a aceitação social plena, trata da categorização das pessoas pela sociedade (ARAUJO et al, 2015). Conforme Araújo et al. (2015, p. 2788), a avaliação social atual da obesidade "apresenta uma fronteira entre o corpo proporcional ("normal") e o que tem gordura - e esse limite é constantemente negociado com as ciências da saúde e a cultura" -. Assim, a obesidade é definida como "um atributo negativo conferido a um indivíduo que, por meio de relações entre determinados atributos e estereótipos, sofre discriminação, manifestação comportamental do preconceito, mesmo que de maneira inconsciente" (BOSI et al., 2006, p. 02).

Quando se trata da atuação do nutricionista, a relação entre identidade profissional e estigma social emerge, principalmente, quanto ao encaixe do profissional dentro de padrões de beleza reconhecidamente aceitos pela sociedade. Para as nutricionistas que não se enquadram no padrão de magreza vigente, a contradição entre as premissas sobre a profissão e seu estado de morbidade deixa o debate mais complexo, "pois a dificuldade de 
controle do próprio peso as coloca em conflito com sua identidade profissional" (ARAUJO et al., 2015, p. 2789).

O presente estudo problematiza, desse modo, a dimensão do vínculo entre identidade profissional e estigma social quanto ao perfil do profissional da Nutrição. Para tanto, o objetivo dessa pesquisa foi verificar se há interferência de estereótipos na percepção do profissional nutricionista e se há um perfil almejado desses pelo mercado de trabalho. Os estereótipos parecem ser, atualmente, fatores de impacto considerável para a escolha do profissional em áreas em que as mulheres são a maioria; e fazer notar a influência desses estigmas sociais, em especial, na constituição do perfil profissional do nutricionista, poderá contribuir para discussões sobre o modo como os modelos sociais determinam a valoração do profissional da área da Nutrição, tendo em vista que há poucos estudos acerca da temática.

A pesquisa descrita neste artigo visa promover esclarecimentos sobre a relação entre estereótipo e perfil profissional. Nesse intento, utiliza, como objeto de estudo, a profissão Nutrição para discutir a temática supracitada. Ainda, o campo recoberto pelo estudo possibilita um espaço de reflexão a respeito da profissão em questão e a própria atuação dos profissionais quanto ao enfrentamento sociocultural diante de oportunidades de emprego, e se esses, de algum modo, são comparados a quaisquer outros profissionais ou são instruídos a se adequarem aos padrões corpóreos vigentes. Na sequência, são apresentados os procedimentos adotados e os instrumentos de análise utilizados para efetivar o objetivo da pesquisa.

\section{METODOLOGIA}

Adotou-se, neste estudo, a abordagem quanti-qualitativa, e a coleta, organização e análise do corpus correspondem à primeira etapa da pesquisa. O corpus foi composto por 27 respostas obtidas em um questionário semiestruturado no formato do aplicativo do Google "Formulário Google", o qual foi enviado para grupos de Nutrição, estudantes de nutrição e nutricionistas de todo o Brasil via as redes sociais WhatsApp e Instagram. O formulário permaneceu disponível durante o período 10 de setembro a 24 setembro de 2019. Considera-se que a pesquisa descrita aqui não tenha cunho invasivo porque se trabalhou, majoritariamente, com dados coletados via formulário on-line, em que não há contato entre 
pesquisador e participante, de modo que não é possível associá-la a nenhum grupo, pessoa ou lugar específico.

Destaca-se também que o princípio da autonomia (MINISTÉRIO DA SAÚDE, RESOLUÇÃO № 466, 2012), no que tange à capacidade do sujeito de decidir por sua vontade própria responder ao formulário ou não, foi respeitado por meio do Termo de Consentimento Livre e Esclarecido (TCLE), encaminhado com o formulário. A técnica de pesquisa aplicada, para a interpretação das respostas obtidas, foi a análise de conteúdo. Esse tipo de análise é um procedimento para o tratamento de dados que visa à identificação do que está dito sobre um tema específico (BARDIN, 1977). Ressalta-se, ainda, que não houve nenhum tipo de interferência (correção) nas respostas analisadas. O formulário foi composto pelas seguintes questões, expostas no Quadro 1:

Quadro 1 - Instrumento de coleta de dados.

Conforme Araújo et al., (2015, p. 2788), a avaliação social atual da obesidade "apresenta uma fronteira entre o corpo proporcional ("normal") e o que tem gordura - e esse limite é constantemente negociado com as ciências da saúde e a cultura". Assim, a obesidade é definida como "um atributo negativo conferido a um indivíduo que, por meio de relações entre determinados atributos e estereótipos, sofre discriminação, manifestação comportamental do preconceito, mesmo que de maneira inconsciente" (OBARA et al., 2018, p. 02). Araújo et al., (2015) aponta, ainda, que nutricionistas relataram já terem sofrido algum tipo de preconceito devido à sua aparência física. O estudo destaca que as nutricionistas que foram entrevistas, durante a busca pelo corpo magro, acessaram dietas que fugiam ao discurso acadêmico. Muitas reportaram utilizar dietas que rompiam com o domínio técnico-científico conferido pela academia (ARAUJO et al., 2015).

1. Em sua opinião, há relação entre "estar/ser magro" e "estar/ser saudável"? Explique.

2. Você já passou por alguma situação em que a sua aparência física foi relacionada, de algum modo, à sua profissão? Caso a sua resposta seja sim, poderia compartilhar essa experiência conosco? 
A segunda etapa do estudo constituiu-se de um levantamento documental realizado a partir da coleta de dados em bancos de seletivas de emprego, no período de junho a setembro de 2019. Essa fase da pesquisa teve o objetivo de mapear possíveis especificidades a serem cumpridas pelo profissional e identificar se havia alguma menção à aparência física ou à condição social. Primeiramente, foi feito um mapeamento no Google para verificar a ocorrência e a recorrência de tais informações. A seguir, foram definidas as seguintes fontes de pesquisa: Agrobase oportunidade (2011), Indeed (2012) e Trabalha Brasil (2018), sites que permitem acesso à pesquisa e solicitação de vagas de emprego para todo o Brasil.

O Agrobase oportunidade é um site que possibilita a busca por vagas de emprego e possui um espaço amplo de pesquisa, no qual o profissional escolhe a opção de sua área de atuação. Ainda, esse site apresenta as vagas que estão disponíveis na área (emprego, estágio ou trainee), podendo ser acessado a partir do link: https://www.agrobase.com.br/oportunidades/.

Já o Indeed é um site de pesquisa de oportunidades de emprego mais objetivo. Ao pesquisar nele, é possível inserir a cidade desejada, pois, na página de abertura, há uma aba para a escolha da área e outra para seleção da cidade pretendida. Após a escolha, a busca se define em vagas para determinada região. Ele pode ser acessado a partir do link: https://www.indeed.com.br/jobs?q=nutricioista+\&l=santo+angelo.

Assim como o site Indeed, o Trabalha Brasil é um site objetivo de busca por oportunidades de emprego. Sua página de abertura também possui abas para escolha da área e da cidade pretendida, podendo ser acessado a partir do link: https://www.trabalhabrasil.com.br/.

A análise dos sites foi feita a partir do levantamento dos requisitos exigidos para a contratação de um Profissional Nutricionista e com o intuito de se verificar a possibilidade da existência de alusão à aparência física do candidato. Essa delimitação foi realizada com o propósito de se identificar se nessas seletivas e ofertas de emprego era exigido um perfil profissional que atendesse aos padrões sociais e culturalmente definidos quanto à aparência física e à condição social do candidato. Por fim, foi feito um cruzamento dos dados levantados com discussões sobre a constituição da identidade do profissional de Nutrição a 
partir da identificação do modo como os padrões estéticos, sociais e culturalmente estabelecidos, podem interferir na valoração desse profissional no mercado de trabalho.

Na próxima seção, os dados levantados na pesquisa são quantificados, descritos e ilustrados por meio de fragmentos extraídos do corpus de análise.

\section{DESCRIÇÃO DOS RESULTADOS}

A primeira questão do instrumento de coleta de dados se referia à opinião dos participantes sobre as noções de "estar/ser magro" e "estar/ser saudável". Para essa questão, foram obtidas um total de 27 respostas, 20 para "não" e 7 (sete) para "sim", conforme a Tabela 1.

Tabela 1 - Quantitativo de repostas para a questão 1 do questionário on-line: Em sua opinião, há relação entre "estar/ser magro" e "estar/ser saudável”?

Não

Sim

A Tabela 1 sugere certo consenso entre os profissionais de que não há relação entre "ser e estar magro" com "ser e estar saudável". A seguir, alguns excertos ilustram o conteúdo textual das respostas que não associaram a noção de magreza à noção de saúde.

"Não. Magreza não significa estar/ser saudável, o indivíduo pode estar/ser magro por outros motivos, inclusive por alguma patologia por consequência, ou não, dos hábitos não saudáveis".

“(...) Mesmo a obesidade sendo um fator de risco para várias doenças, ser magro ou estar magro não quer dizer estar ou ser saudável, pois uma pessoa magra pode desenvolver as mesmas patologias de uma pessoa obesa, visto que há vários fatores de risco para diversas doenças e não só a obesidade". 
"Não pois o fato de ser magro não garante saúde como temos o caso de anorexia e bulimia além disso pessoas das quais não apresentam esse distúrbio podem ter varias outras confissões como no caso do diabetes tipo um ou um eutrofico com o perfil lipídico alterado".

"Ser magro não tem relação nenhuma com saúde, ser saudável é saber fazer escolhas alimentares independente da sua condição física. Boas escolhas implicam na boa manutenção do peso".

"Não. Para determinar o estado de saúde precisamos de diagnóstico baseado em exames laboratoriais, sinais e sintomas".

"Não considero um marco (uma relação), pois nem sempre o indivíduo estando ou sendo magro é ou está saudável. Eu acho que essa relação se dá pelo marketing social, que sinônimo de saúde é magreza!"

A interpretação das respostas sugere que os profissionais apontam que, embora a obesidade possa ser um fator de risco para uma série de doenças, não há uma relação direta dela com a saúde. Para a maioria dos profissionais que responderam a essa questão, a noção estética não foi fator orientador para responder ao questionamento.

Na última resposta, o participante da pesquisa destaca que há certa interferência de estereótipos como mecanismos para reiterar a relação entre magreza e saúde, ratificando o papel das mídias nesse aspecto (“(...) acho que essa relação se dá pelo marketing social, que sinônimo de saúde é magreza!). Freitas et al. (2010, p. 390) salienta que "o padrão atual de beleza física ocidental, proposto pela publicidade e pela mídia, é o da figura longilínea".

Quanto ao conteúdo das respostas negativas, pode-se observar que os profissionais indicaram o fato de que nem sempre é uma escolha "estar/ser magro" e/ou "estar/ser saudável", haja vista a interferência de fatores como: tipo de alimentação, hábitos de vida, avaliações bioquímicas, casos individualizados.

As respostas afirmativas, para a questão do instrumento de coleta de dados: $E m$ sua opinião, há relação entre "estar/ser magro" e "estar/ser saudável"?, respaldaram-se, 
basicamente, na relação de risco entre sobrepeso e doenças associadas a casos individualizados, conforme ilustram os excertos a seguir.

"sim. Os estudos já mostraram que a obesidade é um estado inflamatório, então não teria como ser gordinho e ser 100\% saudável. Mas também não é garantido que o magro te saúde. Acredito que a forma como a pessoa vê, como ela se sente e o ambiente em que ela vive determinam muito sobre o quão saudável ela está".

"Acredito que sim, mas até certo ponto. Magreza não é sinônimo de saúde, bem como o sobrepeso não é sinônimo de doença. Mas, conforme a literatura evidencia, o excesso de peso corporal é um fator de risco importante para o desenvolvimento de distúrbios metabólicos e doenças crônicas não transmissíveis. Dessa forma, acredito que exista uma relação entre ser magro e ser saudável, mas, acima de tudo, defendo a ideia de avaliarmos criticamente cada caso antes de determinarmos associações".

"Talvez, 'somos o que comemos', porem depende muito, vários fatores, genético por exemplo".

O conteúdo das respostas indica que existe certa ponderação por parte dos profissionais na discussão dessa temática, e isso é marcado por expressões linguísticas como: "mas" e "talvez" em negrito nos trechos selecionados.

Para a segunda questão do instrumento de coleta de dados, acerca das experiências vividas (se os participantes já passaram por alguma situação em que a sua aparência física foi relacionada de algum modo a sua profissão), obtiveram-se 21 respostas, conforme a Tabela 2. Em seis formulários, os participantes responderam somente à questão 1. Também havia a solicitação de que, se a resposta fosse afirmativa, eles/elas compartilhassem a experiência. De acordo com o quantitativo obtido, a maioria dos profissionais já passou por alguma situação em que a sua aparência física foi relacionada, de algum modo, à sua profissão.

Tabela 2 - Quantitativo das respostas negativas e afirmativas para a questão 2 do instrumento de coleta de dados: Você já passou por alguma situação em que a sua aparência física foi relacionada, de algum modo, à sua profissão? 
Sim

Não
16

5

A seguir, são apresentadas as respostas de participantes que relataram situações em que a sua aparência física foi associada à profissão em três ambientes: na esfera universitária - de formação profissional -, o primeiro relato; no ambiente profissional, no segundo relato; e no familiar, no terceiro relato. Optou-se por reproduzi-los na íntegra em função do detalhamento feito pelos participantes, que retrata a associação entre aparência física e a profissão de nutricionista e as sanções sociais que profissionais da área sofrem.

"Sim. Diversas situações já aconteceram desde a graduação em Nutrição. Já ouvi de pessoas de meu convívio, que nutricionista bom é nutricionista magro; que eu estava escolhendo uma profissão que era uma prisão que eu nunca ia poder me "descuidar" e engordar, porque na minha profissão isso não era permitido; que eu precisava dar o exemplo para os outros e que, portanto, precisava ser magra; que eu tinha que comer salada, frutas $e$ pão integral, caso contrário eu não seria boa o suficiente. Mas existiu uma situação bastante cruel entre eu e uma amiga querida e colega de profissão. Essa colega iria dar uma palestra em uma comunidade rural e foi substituída por outra colega mais magra para que a imagem das nutricionistas não fosse abalada. Foi algo que ficamos sabendo só no ano seguinte, quando estávamos planejando as atividades com a mesma comunidade novamente, e todos falavam que não queriam que a nutricionista gordinha fosse palestrar".

"Sim, muitas. Sou baixa de estatura e tenho peso 'normal', sendo de modo geral, pequena. E sempre fui isso é muito mais uma questão de genética do que hábitos saudáveis. Comecei a trabalhar em prefeitura, e no inicio sempre fui muito comparada com a nutricionista anterior, não a conheço, mas segundo comentários dos colegas, ela era 'gordinha' e 'precisava emagrecer', soube inclusive que enquanto trabalhava lá, ela realmente emagreceu, o que suponho que tenha sido muito motivado por comentários recebidos. Outro momento, foi em atendimento clínico, quando questionei se a pessoa já havia realizado alguma consulta com nutricionista, a resposta foi: 'sim, fui consultar com uma, mas cheguei lá e ela era gorda, como vai me ajudar se não consegue nem se ajudar? 
Não confiei, não voltei na reconsulta.' Lembro de ter ficado muito abalada com esse relato, porque o que levou a procurar outra profissional (no caso eu) foi a aparência física, não dando chance nem para conhecer o trabalho que a outra nutricionista poderia desenvolver. $E$ por fim, um comentário de um colega de trabalho: 'Desde que começou a trabalhar aqui até você engordou, hein?!". Além disso, vale destacar, a nível de curiosidade, os números momentos constrangedores durante uma refeição, onde SEMPRE alguém faz um comentário ou questionamento sobre o que você esta comendo e julgando o prato e a escolha de alimentos".

"Sim... a própria família, (algo do tipo, mas como tu como tanto, nutricionista tem que dar o exemplo)".

O conteúdo das respostas sugere que há uma rotulação feita pela sociedade, a qual associa a profissão aos estereótipos de magreza e suposta perfeição corporal, em função da sua natureza e da própria historicidade. Logo, parece que se considera o padrão antropométrico estético de "magreza" como um critério para aferir valor/competência profissional, sustentando e reproduzindo discursos que associam a magreza à saúde. Dessa maneira, a obesidade é estigmatizadora para esses indivíduos, ela pode produzir "discriminação, preconceito e exclusão social" (MELO et al., 2017, p. 306). Há um outro aspecto que pode incidir diretamente sobre a profissão de nutricionista, conforme Everett (1990), citado em Bellizzi e Hasty, (1998), a saber: o quanto a associação entre a aparência de uma pessoa e um padrão físico considerado desagradável pode influenciar, negativamente, a venda de um produto ou serviço. As diferentes formas de mídia, tais como Instagram e Facebook, por exemplo, estão a serviço da indústria da beleza e participam de forma ativa desse processo, "difundindo e atendendo as leis do mercado capitalista e aos parâmetros criados para um corpo considerado belo, que atualmente é atribuído a imagem magra, jovial e esguia" (COPETTI; QUIROGA, 2018, p. 164).

A análise do conteúdo indica, ainda, que a associação entre aparência física e o perfil do profissional da Nutrição parecem encontrar respaldo na cultura, já que a profissão em questão não define padrão corpóreo para o profissional, segundo o Conselho Federal de Nutricionistas. Conforme Melo et al (2017, p. 306), a cultura ocidental valoriza a magreza e, 
por isso, a perfeição corpórea é assunto constante nas mídias, que "sempre destacam a dieta, a forma perfeita, os medos da gordura e como não engordar e ter um corpo perfeito".

Quanto às respostas negativas, foram cinco no total. Em uma delas, o participante detalhou o "não" indicando que parece haver uma associação entre o profissional da área e o estereótipo de magreza ("Não, mas já ouvi pessoas dizendo que não consultariam com uma nutricionista acima do peso".), de acordo com o que foi evidenciado em estudos prévios, tais como os de Araujo et al. (2015); Bosi et al. (2006) e Obara et al. (2018).

A segunda etapa da pesquisa, a análise documental, compreendeu a coleta de informações nos bancos de seletivas de emprego Agrobase oportunidade, Indeed e Trabalha Brasil. Para fins de visualização, o Quadro 2 demonstra os critérios utilizados na análise dos sites de ofertas de emprego. Nesta etapa da pesquisa, buscou-se verificar se esses sites faziam qualquer tipo de relação entre as vagas oferecidas para nutricionistas e aparência física.

\section{Quadro 2 - Mapeamento dos sites Agrobase oportunidade, Indeed e Trabalha Brasil.}

\begin{tabular}{|c|c|c|}
\hline Sites & Sim & Não \\
\hline \multicolumn{3}{|c|}{ Apresenta vaga para nutrição } \\
\hline Agrobase oportunidade & $x$ & \\
\hline Indeed & $x$ & \\
\hline Trabalha Brasil & $x$ & \\
\hline \multicolumn{3}{|c|}{ Apresenta descrição da vaga oferecida } \\
\hline Agrobase oportunidade & $\mathrm{x}$ & \\
\hline Indeed & $x$ & \\
\hline Trabalha Brasil & $x$ & \\
\hline Solicita especificações & $x$ & \\
\hline Agrobase oportunidade & & $x$ \\
\hline Indeed & & $x$ \\
\hline Trabalha Brasil & & $x$ \\
\hline \multicolumn{3}{|c|}{ Solicita currículo de formação } \\
\hline Agrobase oportunidade & $\mathrm{x}$ & \\
\hline Indeed & $x$ & \\
\hline Trabalha Brasil & $x$ & \\
\hline \multicolumn{3}{|l|}{ Faz menção à forma física } \\
\hline Agrobase oportunidade & & $x$ \\
\hline Indeed & & $x$ \\
\hline Trabalha Brasil & & $x$ \\
\hline \multicolumn{3}{|c|}{ Faz menção à identidade do profissional } \\
\hline Agrobase oportunidade & & $x$ \\
\hline Indeed & & $x$ \\
\hline Trabalha Brasil & & $x$ \\
\hline
\end{tabular}


A análise do conteúdo dos bancos de seletivas de emprego referentes a vagas para a área de Nutrição não forneceu material de pesquisa. No entanto, conforme o Quadro 2, verificou-se que há um padrão a ser seguido nesses sites: a solicitação de formação na área. Não há, portanto, em nenhum dos itens analisados, alusão às características físicas do candidato.

Assim, pressupõe-se que a aparência seja avaliada somente no momento da entrevista, uma vez que os sites de ofertas de emprego analisados são, geralmente, plataformas sem vínculo com as empresas as quais prestam o serviço e, por isso, necessitam manter um padrão de divulgação e mediação do contato entre o candidato à vaga e a empresa. Esse aspecto também pode estar relacionado ao fato de que os sites de emprego podem sofrer punições legais caso façam menção às questões físicas, visto que a Constituição Federal (1988) proíbe, no artigo 3ํㅡ, inciso IV, preconceitos de origem, raça, sexo, cor, idade e quaisquer formas de discriminação.

\section{CONSIDERAÇÕES FINAIS}

A presente pesquisa teve, como objetivo, verificar a possível interferência de padrões estéticos estereotipados de magreza na percepção e na constituição do perfil do profissional da área de Nutrição. Tratou-se de um estudo quanti-qualitativo efetivado por meio de um questionário semiestruturado, disponibilizado on-line, o qual foi direcionado aos profissionais Nutricionistas e de análises de seletivas de emprego voltadas à Nutrição, direcionados às agências. As seletivas de emprego não forneceram material de análise que pudesse responder ao que foi proposto no objetivo geral da pesquisa.

Os resultados obtidos via o questionário semiestruturado indicaram que, no imaginário social, parece existir uma relação entre o padrão antropométrico do nutricionista e o estereótipo social de magreza, que é culturalmente entendido como um atributo do profissional da área, segundo ilustraram os excertos na seção de análise e discussão dos resultados. Observou-se, nas respostas analisadas, que não corresponder ao padrão antropométrico vigente de magreza parece ser um obstáculo para o nutricionista.

Logo, há um alinhamento entre a aparência física desse profissional, em termos de padrão antropométrico, e a percepção sobre a área em conformidade com os padrões estéticos vigentes de magreza. Constata-se que o estereótipo de magreza parece ser um aspecto constitutivo da identidade do nutricionista. 
Isso pode colocar esse indivíduo em embate pessoal, conforme indicou também o estudo de Araújo et al. (2015), pois ele/ela se vê obrigado(a) a corresponder às exigências do contexto social para não ser excluído do mercado de trabalho. O estudo ainda afirmou que, em função desse aspecto, os profissionais iam de encontro ao conhecimento científico da área para tentar se encaixarem no estereótipo de magreza vigente e aceito na sociedade contemporânea. Além disso, independente de o peso não dever ser uma referência para definir a qualidade de um profissional, tanto a obesidade quanto à magreza podem gerar prejuízos à saúde. A Organização Mundial de Saúde (OMS) define saúde como "um estado de completo bem-estar físico, mental e social, e não consiste apenas na ausência de doença ou de enfermidade" (OMS, 1946). Tal conceito de saúde orienta para a compreensão de que não se trata apenas de como o corpo humano se apresenta visivelmente, mas sim da relação entre um conjunto de aspectos que ultrapassam a aparência física.

Ressalta-se que a pesquisa se resumiu a um pequeno número de participantes, já que havia um tempo reduzido para sua realização. Em função disso, recomenda-se que haja uma ampliação de modo a corroborar ou a refutar os resultados. Quanto às limitações do estudo, observou-se a baixa adesão dos profissionais da área à pesquisa. Ademais, houve uma falha processual, a qual impossibilitou que uma parte da pesquisa, referente à aplicação de um questionário semiestruturado a uma parcela representativa da sociedade, pudesse ser somada ao estudo para implementar a discussão sobre a percepção que a sociedade tem sobre o perfil do profissional da área de Nutrição. Cabe destacar, também, que não foi possível determinar se ocorreu percepção de desvalorização do profissional devido ao seu peso ou à sua estética. $O$ que os resultados sugerem é a existência de uma cobrança em relação à profissão analisada e a aparência física.

\section{REFERÊNCIAS BIBLIOGRÁFICAS}

AGROBASE OPORTUNIDADES. Disponível em: <https://www.agrobase.com.br/oportunidades/>. Acesso em: 01 out. 2018. Acesso em: 12 outubro. 2018.

ARAÚJO, K. L.; PENA, P. G. L; FREITAS, M. C. S. Sofrimento e preconceito: trajetórias percorridas por nutricionistas obesas em busca do emagrecimento. Revista Ciência \& Saúde Coletiva, p. 2787-2796, 2015. 
BARDIN, L. Análise de conteúdo. Lisboa: Edições, 1977.

BELLIZZI, J. A.; HASTY, R. W. Territory assignment decisions and supervising unethical selling behavior: The effects of obesity and gender as moderated by jobrelated factors. The Journal of Personal Selling \& Sales Management, v. 18, n. 2, p. 35-49, 1998.

BOSI, M. L. M.; LUIZ, R. R.; MORGADO, C. M. C. et al. Autopercepção da imagem corporal entre estudantes de nutrição: um estudo no município do Rio de Janeiro. Revista Brasileira de Psiquiatria, p. 108-113, 2006.

BRASIL, Constituição Federativa do Brasil. Brasília: Senado Federal, 1988. Disponível em: https://www.senado.leg.br/atividade/const/con1988/con1988 06.06.2017/art 3 .asp\#: :te xt=III\%20\%2D\%20erradicar\%20a\%20pobreza\%20e, quaisquer\%20outras\%20formas\%20de\%2 Odiscrimina\%C3\%A7\%C3\%A30. Acesso em 02 jun. 2020.

BRASIL, Conselho Nacional de Saúde. Resolução no 466/2012 - Dispõe sobre pesquisa envolvendo seres humanos. Brasília, DF: Ministério da Saúde, 2012. Disponível em http://bvsms.saude.gov.br/bvs/saudelegis/cns/2013/res0466 1212 2012.html\%3E. Acesso em 02 jun. 2020.

CONSELHO FEDERAL DE NUTRICIONISTAS - CFN. Disponível em: http://www.cfn.org.br/index.php/biblioteca/page/3/.> Acesso em: 12 out. 2019.

COPETTI, A. V. S.; QUIROGA, C. V. A influência da mídia nos transtornos alimentares e na autoimagem em adolescentes. Revista Psicologia IMED, v. 10, n. 2, p. 161-177, 2018. Disponível em <http://pepsic.bvsalud.org/scielo.php?script=sci_arttext\&pid=S217550272018000200011\&lng=pt\&nrm=iso>. Acesso: 03 jun. 2020. http://dx.doi.org/10.18256/2175-5027.2018.v10i2.2664.

FREITAS, C. M. S. M.; LIMA, R. B. T.; COSTA, A. S. et al. O padrão de beleza corporal sobre o corpo feminino mediante o IMC. Revista Brasil, v. 24, n. 3, p. 389-404, 2010.

INDEED. Disponível em: < https://www.indeed.com.br/jobs?q=nutricioista+\&l=santo+angelo $>$. Acesso em: 01 out. 2018.

IRIART, J. A. B.; CHAVES, J. C.; ORLEANS, R. G. Culto ao corpo e uso de anabolizantes entre praticantes de musculação. Caderno de Saúde Pública, v. 25, n.04 p. 773-782, 2009.

MELO, F. V. S.; FARIAS, S. A.; KOVACS, M. H. Estereótipos e estigmas de obesos em propagandas com apelos de humor. Revista O\&S, v. 24, n. 81, p. 305-324, 2017.

OBARA, A. A.; VIVOLO, S. R. G. F.; ALVARENGA, M. S. Preconceito relacionado ao peso na conduta nutricional: um estudo com estudantes de nutrição. Caderno de Saúde Pública, v. 34, n. 8, p. 01-14, 2018. 
ORGANIZAÇÃO MUNDIAL DA SAÚDE - OMS. Carta da Organização Mundial de Saúde, 1946. Disponível em: < http:// www.onuportugal.pt/oms.doc. > Acesso em: 02 jun. 2020.

SILVA, J. E. F.; GIORGETTI. K, S.; COLOSIO, R, C. Obesidade e sedentarismo como fatores de risco para doenças cardiovasculares em crianças e adolescentes de escolas públicas de Maringá, PR. Revista Saúde e Pesquisa, v. 2, n. 1, p. 41-51, 2009.

SONATI, J. G. et al. Análise comparativa da qualidade de vida de adultos e idosos envolvidos com a prática regular de atividade física. Revista Brasil, v.17, n.04, p. 731-739, 2014.

SOUZA, L. K. C. S.; CAMPOS, F. M.; KRAEMER, F. B. et al. Gênero e formação profissional: considerações acerca do papel feminino na construção da carreira de nutricionista. Revista Nutrição e Saúde, v.11, n.03, p. 773-788, 2016.

TRABALHA BRASIL. Disponível em: <https://www.trabalhabrasil.com.br/>. Acesso em: 01 out.2018.

Recebido em 22 de abril de 2020. 